\title{
Relationship between performance test and body composition/physical strength characteristic in sprint canoe and kayak paddlers
}

This article was published in the following Dove Press journal:

Open Access Journal of Sports Medicine

19 June 2015

Number of times this article has been viewed

\author{
Saki Hamano' \\ Eisuke Ochi \\ Yosuke Tsuchiya ${ }^{3}$ \\ Erina Muramatsu ${ }^{4}$ \\ Kazuhiro Suzukawa ${ }^{5}$ \\ Shoji Igawa' \\ 'Department of Sports Nutrition, \\ Nippon Sport Science University, \\ Yokohama, Kanagawa, ${ }^{2}$ Graduate \\ School of Education, Okayama \\ University, Okayama, ${ }^{3}$ Laboratory \\ of Health and Sports Sciences, \\ Meiji Gakuin University, Yokohama, \\ Kanagawa, ${ }^{4}$ Department of Natural \\ Sciences, Nippon Sport Science \\ University, Setagaya, Tokyo, \\ ${ }^{5}$ Laboratory of Preventive Medicine \\ and Public Health, Nippon Sport \\ Science University, Setagaya, Tokyo, \\ Japan
}

Objective: Canoe sprint is divided into canoe and kayak. The difference between the two competitions is in physical performance. The aim of the present study was to compare and investigate the relationship between physical characteristics and fitness between the two canoe sprint competitors.

Methods: Subjects were 11 canoe paddlers (C) and 12 kayak paddlers (K). They underwent anthropometric characteristics, body composition and fitness tests, and $120 \mathrm{~s}$ all-out tests using a canoe and kayak ergometer. The unpaired $t$-test was used to test for significant differences between disciplines, while Pearson's correlation coefficient was used to examine the association between each measurement item and the performance test.

Results: The age, height, body mass, body mass index, and total body fat were, C: $20.6 \pm 0.9$ yr, $172.8 \pm 5.2 \mathrm{~cm}, 70.8 \pm 7.8 \mathrm{~kg}, 23.7 \pm 1.9,14.4 \% \pm 3.5 \%$; and $\mathrm{K}: 19.7 \pm 1.2 \mathrm{yr}, 172.8 \pm 5.3 \mathrm{~cm}$, $69.5 \pm 7.8 \mathrm{~kg}, 23.2 \pm 2.1,12.1 \% \pm 3.6 \%$, respectively. No significant differences were seen in any of the items for physical characteristics or fitness between $\mathrm{C}$ and $\mathrm{K}$. A correlation analysis of performance tests and each measurement item revealed a positive correlation with low-speed isokinetic knee extension and flexion strength for $\mathrm{C}$ only (extension: $r=0.761$; flexion: $r=0.784$; $P<0.01)$. In addition, performance tests were positively correlated with the circumference of arm (upper arm: $r=0.876$; forearm: $r=0.820 ; P<0.01$ ) and lower limb (thigh: $r=0.781$; calf: $r=0.753 ; P<0.01)$ in $\mathrm{C}$ and with height $(r=0.549, P<0.05)$, arm span $(r=0.639, P<0.05)$, and leg length $(r=0.621, P<0.01)$ in $\mathrm{K}$.

Conclusion: We suggest that the factors correlating with the performance test differ depending on the competitions.

Keywords: canoe sprint, kayak, body composition, isokinetic strength, morphology

\section{Introduction}

Canoe sprint is an Olympic sport that is divided into two disciplines: canoe (C), in which the athlete paddles on one side while kneeling on one knee, and kayak (K), in which the athlete paddles on both the left and the right side in a sitting position. It is a sport in which athletes compete to finish a linear course $(1,000,500,200 \mathrm{~m})$ setup in standing water without flow, the fastest. In a review, it has been shown that medical and surgical problems such as hydrocution and hypothermia in canoe and kayak paddlers have been identified. ${ }^{1}$

Athletes are trying to adapt their anthropometric characteristics, body composition, and fitness specifically to this sport by continuing long-term training. ${ }^{2}$ Robinson et $\mathrm{al}^{3}$ showed that the anthropometric characteristics of the athlete has a large impact on competitiveness in canoe sprint. Furthermore, Ackland et $\mathrm{al}^{4}$ reported that elite canoe sprinters have better developed upper bodies, smaller buttocks, and greater lean
Correspondence: Eisuke Ochi

Graduate School of Education,

Okayama University, 3-I-I, Tsushimanaka,

Kita, Okayama 700-8530, Japan

Tel +818625 I 7750

Fax +8I 862517750

Email eisukeochi@cc.okayama-u.ac.jp
Open Access Journal of Sports Medicine 2015:6 191-199

submit your

http://dx.doi.org/10.2147/OAJSM.S82295 (c) (i) (2) ๑ 2015 Hamano et al. This work is published by Dove Medical Press Limited, and licensed under Creative Commons Attribution - Non Commercial (unported, v3.0) License. The full terms of the license are avalabble at http://creativecommons.orglicicenses/by-nc/3.0/. Non-commercial uses of the work are permitted without any further

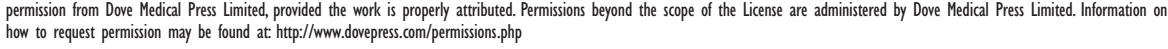


body mass than athletes from other disciplines and ordinary adults. In terms of fitness, kayak paddlers have both high aerobic and anaerobic capacities and have been shown to lift the same maximum weight as judoists and rugby players in bench press and bench pull. ${ }^{5}$ These reports suggest that Olympic medalists and athletes competing in international competitions have a specific physique, particularly in these sports. However, few reports have investigated the isokinetic muscle strength in canoe and kayak paddlers.

As stated earlier, canoe sprint is divided into a discipline using canoes and a discipline using kayaks. These two competitions greatly differ in terms of the paddles used and the movement pattern. The speed of the boat also differs between the two groups. A previous study reported that the abdominal and scapular skinfold thicknesses of kayak paddlers were lesser than those of canoes paddlers. ${ }^{6}$ Other sports to date have described how body composition and fitness differ depending on the specialist discipline and the position. In a study that investigated differences in the physical characteristics of ordinary male university students and those who participated in competitive swimming, handball, soccer, rugby, athletics (long-distance running, sprint, jumping events, and throwing), judo (lightweight, middleweight, and heavyweight), and gymnastics, anthropometric characteristics and body composition were found to differ depending on the specialist discipline. ${ }^{7}$ A report investigating the body composition and fitness of collegiate American Football players found that body fat was the highest in linebackers, followed by middle linebackers and backs, in that order. They also found that backs had greater running capacity than other positions. ${ }^{8}$ Tsuchiya et al ${ }^{9}$ measured isokinetic knee extension and flexion force in male lacrosse players and reported that midfielders have significantly higher isokinetic knee flexion strength at high speeds than do attackers. While other reports have elucidated the association between isokinetic strength and performance in sports such as athletics and soccer, ${ }^{10,11}$ no studies have investigated differences in anthropometric characteristics and fitness between canoe and kayak paddlers. It is important to elucidate the anthropometric characteristics, body composition, and fitness of canoe and kayak paddlers when planning training programs and discovering talented athletes.

Previous studies have revealed that kayak paddlers primarily develop muscle mass in the muscle groups of the upper body, including the upper limbs and the trunk. ${ }^{12-14}$ In addition, a study that investigated the correlation between $200 \mathrm{~m}$ sprint time and anthropometric characteristics in kayak paddlers demonstrated significant correlations between $200 \mathrm{~m}$ sprint time and upper arm, forearm, and chest circumference. ${ }^{15}$ The canoe paddlers could be expected to have stronger correlations between the performance and the anthropometries of the lower limbs and muscle strength because they need to perform larger torque while kneeling on one knee, while kayak paddlers exert force in a sitting position. However, no study has investigated the correlation between performance and the anthropometric characteristics and muscle strength of both canoe and kayak paddlers. Therefore, it is needed to clarify the associations between these factors such as anthropometric characteristics, body composition, and fitness affecting the performance in canoe and kayak paddlers.

In this study, we, therefore, had two aims. First, we compared the anthropometric characteristics, body composition, and fitness between canoe and kayak paddlers. Second, we investigated how the performance test is associated with anthropometric characteristics, body composition, and fitness in canoe and kayak paddlers. We hypothesized that kayak paddlers have lesser trunk fat than canoe paddlers, and canoe paddlers have higher leg strength than kayak paddlers. In addition, we also hypothesized that leg strength related to postural maintenance in canoe is significantly correlated with performance.

\section{Materials and methods Subjects}

Subjects were 11 male canoe paddlers (C; $20.6 \pm 0.9 \mathrm{yr}$ ) and 12 male kayak paddlers (K; $19.7 \pm 1.2 \mathrm{yr}$ ) in university (total 23 individuals). The career of canoe paddlers was $6.5 \pm 1.4 \mathrm{yr}$ and that of kayak paddlers was $6.0 \pm 2.4 \mathrm{yr}$. Each subject has trained on water 3-4 h/day, 3 times a week, and trained by a canoe ergometer 3-4 h/day, 3 times a week. Two subjects of this study had attended an international competition and 12 subjects had attended a national competition. All subjects gave their written informed consent after being given sufficient explanation of the study objectives and content and precautions. This study was approved by the Ethics Committee for Nippon Sports Science University (approval no 014-H24). All measurements of this study were conducted in July 2014.

\section{Anthropometric characteristics}

Anthropometric characteristics was carried out by measuring the length in 15 locations (height, arm span, sitting height, arm length, forearm length, hand length, thigh length, calf length, and foot height) and girth in 8 locations (neck, chest, waist, hip, arm, forearm, thigh, and calf girth) by a tape measure. ${ }^{16}$ We also calculated the length of the upper limbs as the sum of the length of the arm, forearm, and hand; and the length of the lower limbs as the sum of the length of the thigh, calf, and foot. 
The mean value was used as the representative data of bilateral regions. A statistician conducted all the measurements. In addition, body mass index (BMI) was calculated as body weight divided by the square of height $\left(\mathrm{kg} / \mathrm{m}^{2}\right)$.

\section{Body composition}

Dual-energy X-ray absorptiometric (DEXA) scans (Lunar DPX-L, GE Healthcare, Buckinghamshire, UK) were used to measure the body composition. DEXA scanning involved measuring posture in the supine position after subjects removed all metal objects that they were wearing. After measurements were obtained, systemic scan data were divided into four regions: the head, the upper limbs, the lower limbs, and the trunk. The body fat ratio, fat mass, lean body mass, bone mineral content (BMC), and bone mineral density were found for each region, excluding the head. ${ }^{17}$

\section{Physical fitness test}

Maximum oxygen uptake

Maximum oxygen uptake $\left(\mathrm{VO}_{2 \text { max }}\right)$ was measured by an incremental test with a treadmill using a respiratory instrument for measuring metabolism (AE-100i, Minato Medical Science Co Ltd., Tokyo, Japan). Measurements were initiated from $8 \mathrm{~km} / \mathrm{h}$ at an inclination of $1 \%$ and then increased by $2 \mathrm{~km} / \mathrm{h}$ every $3 \mathrm{~min}$. After four stages, the gradient was increased by $1 \%$ every minute and this was continued until the subjects reached exhaustion. ${ }^{18}$ Heart rate was measured simultaneously during exercise, and the heart rate on going all out was designated the maximum heart rate. Blood lactate was analyzed using a blood lactate test meter (Lactate Pro2 LT-1730, Arkray, Kyoto, Japan), for which a trace amount of blood was collected from the fingertip directly, immediately after exercise.

\section{Grip strength, back strength, sit and reach, sit-up}

Hand grip strength was measured twice, alternating between the right and left hands, using an analog dynamometer (Takei Kiki Kogyo, Niigata, Japan). The average of the best recorded measurements for each hand was used as the representative value. Back muscle strength was measured twice using a digital back muscle strength meter (Takei Kiki Kogyo), and the best recorded measurement was used as the representative value. For sit and reach, subjects were seated on the floor with knees fully extended and ankles in neutral dorsiflexion against the box. The subjects were instructed to place one hand on top of the other and slowly reach forward as far as possible while keeping the knees extended. The hands were kept aligned evenly as the subject reached forward along the surface of the box. Each subject practiced the movement twice, and on the third repetition, the sit and reach test score (in centimeters) was recorded as the final position of the fingertips on the ruler. For sit-ups, the subjects adopted a supine position on a mat with both hands slightly clenched and arms crossed in front of the chest, and they performed as many sit-ups as possible in $30 \mathrm{~s}$, with an assistant stabilizing both the knees of each test subject at an angle of $90^{\circ}$.

\section{Abalakov test, squat jump, and one repetition maximum}

A jump meter (Takei Kiki Kogyo) was used for the Abalakov test (ABA) and squat jump (SJ). For ABA, each subject jumped with swinging the arms back behind the body immediately after squatting down until the knees were bent at $90^{\circ}$. For SJ, joint angle of knee was $90^{\circ}$ as the starting position, hands of each subject kept with waist and jumped without arm swing. ABA and SJ measurements were made in $1 \mathrm{~cm}$ units, and the highest value of two attempts was used as the representative value. One repetition maximum (1RM) was measured after warming up. Each subject chose a weight that was achievable, then after a rest of at least several minutes, increased the weight ( $2.5 \mathrm{~kg}$ at a time) and tried again. Each subject measured subsequent weights until they could only repeat one full and correct lift of that weight. ${ }^{19}$

\section{Wingate test}

The Wingate test involved subjects pedaling a bicycle ergometer (PowerMax VIII, Combi, Taito-ku, Tokyo Japan) for a maximum of $30 \mathrm{~s}$ at a load of $7.5 \%$ of their body weight. ${ }^{9}$ The rotational speed was recorded every $5 \mathrm{~s}$, and the peak and mean power were calculated.

\section{Isokinetic strength of knee extensor and flexor muscles}

Isokinetic knee extension (ext) and flexion (flex) strength were measured using an isokinetic dynamometer (Biodex system 3, Biodex, Shirley, NY, USA). Peak torque was calculated by measuring the left and right legs of the subjects at low speed $\left(60^{\circ} / \mathrm{s}\right)$, medium speed $\left(180^{\circ} / \mathrm{s}\right)$, and high speed $\left(300^{\circ} / \mathrm{s}\right)$ while in a sitting position. ${ }^{9}$ The obtained values were shown as the relative value per kilogram of body weight.

\section{Performance test}

The performance test involved exercising all out for $120 \mathrm{~s}$ on a canoe and kayak ergometer (Dansprint, Hvidovre, Denmark). The ergometer was an air resistance one in which the pulling weight changes according to the temperature and humidity. We, therefore, standardized the pulling weight by calibrating the ergometer before all tests (drag resistance 
coefficient, 32).$^{20}$ During the test, the stroke distance, stroke rate, and power exerted per stroke were fed into a personal computer. We also calculated the peak and average power exerted over 120 s. After performing sufficient warm-up, the subjects were instructed to row at full force for $120 \mathrm{~s}$ while the elapsed time and power exerted were monitored. Configurations of the ergometer and stroke rate were left to the subjects. The average power exerted was used as the performance index. We also analyzed blood lactate using a trace amount of blood collected from the fingertip directly after the completion of exercise.

\section{Statistical analysis}

The measurement results of each item are shown as the mean \pm standard deviation. An unpaired $t$-test was used to compare the differences in the mean value of each measurement item between canoe and kayak. In addition, Pearson's correlation coefficient was used to examine the association between each parameter and the performance test. The level of significance was set at less than $5 \%$ for both. The magnitude of correlation was shown based on Cohen's criteria: trivial $(r \leq 0.1)$, small $(0.1<r \leq 0.3)$, moderate $(0.3<r \leq 0.5)$, large $(0.5<r \leq 0.7)$, very large $(0.7<r \leq 0.9)$, and nearly perfect $(r>0.9) .{ }^{21}$ Excel of Windows 2010 was used for all statistical analyses.

\section{Results}

\section{Comparisons of physical characteristics and fitness in canoe and kayak paddlers}

Tables 1 and 2 show the results of anthropometric characteristics and body composition of canoe and kayak paddlers. No significant differences were seen between canoe and kayak for age (C: 20.6 $\pm 0.9 \mathrm{yr} ; \mathrm{K}: 19.7 \pm 1.2 \mathrm{yr}$ ), sports career (C: $6.5 \pm 1.4$ yr; K: $6.1 \pm 2.3 \mathrm{yr}$ ), height (C: $172.8 \pm 5.2 \mathrm{~cm}$; K: $172.8 \pm 5.3$ $\mathrm{cm}$ ), body mass (C: $70.8 \pm 7.8 \mathrm{~kg} ; \mathrm{K}: 69.5 \pm 7.8 \mathrm{~kg}), \mathrm{BMI}(\mathrm{C}$ : $23.7 \pm 1.9 ; \mathrm{K}: 23.2 \pm 2.1)$, and all anthropometric characteristics and body composition items. Similarly, no significant differences in the results of the fitness test was seen between canoe and kayak with respect to all the parameters.

\section{Comparisons of performance test in canoe and kayak paddlers}

Table 3 shows the results of the performance test in canoe and kayak paddlers. Compared with canoe paddlers, kayak paddlers had a significantly higher stroke rate $(\mathrm{C}: 62.0 \pm 3.9$ times/min; K: 113.7 \pm 9.1 times/min; $P<0.001)$, peak exerted power (C: $183.1 \pm 47.6 \mathrm{~W} ; \mathrm{K}: 364.7 \pm 54.9 \mathrm{~W} ; P<0.001)$, and average exerted power $(\mathrm{C}: 120.5 \pm 27.0 \mathrm{~W}$; $: 201.8 \pm 26.4 \mathrm{~W}$;
Table I Comparisons of absolute size characteristics in canoe and kayak paddlers

\begin{tabular}{|c|c|c|c|}
\hline & Canoe & Kayak & $\boldsymbol{P}$ \\
\hline $\mathrm{n}$ & II & 12 & ns \\
\hline Age (yr) & $20.6 \pm 0.9$ & $19.7 \pm 1.2$ & ns \\
\hline Career (yr) & $6.5 \pm 1.4$ & $6.1 \pm 2.3$ & ns \\
\hline Height (cm) & $172.8 \pm 5.2$ & $172.8 \pm 5.3$ & ns \\
\hline Body mass (kg) & $70.8 \pm 7.8$ & $69.5 \pm 7.8$ & $\mathrm{~ns}$ \\
\hline BMI & $23.7 \pm 1.9$ & $23.2 \pm 2.1$ & ns \\
\hline \multicolumn{4}{|c|}{ Anthropometric characteristics } \\
\hline \multicolumn{4}{|c|}{ Segment length } \\
\hline Arm span $(\mathrm{cm})$ & $177.9 \pm 7.2$ & $177.4 \pm 8.0$ & ns \\
\hline Sitting height $(\mathrm{cm})$ & $92.5 \pm 3.6$ & $92.9 \pm 2.3$ & ns \\
\hline Upper limb $(\mathrm{cm})$ & $78.3 \pm 2.8$ & $78.0 \pm 3.2$ & ns \\
\hline Lower limb $(\mathrm{cm})$ & $89.5 \pm 3.8$ & $89.2 \pm 3.3$ & ns \\
\hline \multicolumn{4}{|l|}{ Girth } \\
\hline Neck $(\mathrm{cm})$ & $37.3 \pm 1.8$ & $36.6 \pm 1.8$ & ns \\
\hline Chest (cm) & $94.6 \pm 6.3$ & $93.9 \pm 5.7$ & ns \\
\hline Waist (cm) & $78.9 \pm 4.4$ & $78.6 \pm 5.2$ & ns \\
\hline $\mathrm{Hip}(\mathrm{cm})$ & $92.3 \pm 4.0$ & $91.9 \pm 3.9$ & $\mathrm{~ns}$ \\
\hline $\operatorname{Arm}(\mathrm{cm})$ & $31.5 \pm 2.5$ & $30.5 \pm 2.5$ & ns \\
\hline Forearm $(\mathrm{cm})$ & $26.7 \pm 2.0$ & $27.5 \pm 1.7$ & ns \\
\hline Thigh $(\mathrm{cm})$ & $54.7 \pm 2.8$ & $53.2 \pm 3.3$ & ns \\
\hline Calf $(\mathrm{cm})$ & $36.4 \pm 1.9$ & $36.6 \pm 1.7$ & ns \\
\hline \multicolumn{4}{|l|}{ Body composition } \\
\hline \multicolumn{4}{|l|}{ Body fat } \\
\hline Arms (\%) & $9.1 \pm 2.7$ & $8.2 \pm 2.8$ & ns \\
\hline Legs (\%) & $15.6 \pm 3.7$ & $13.1 \pm 3.9$ & ns \\
\hline Trunk (\%) & $14.8 \pm 3.7$ & $12.8 \pm 3.9$ & ns \\
\hline Total body (\%) & $14.4 \pm 3.5$ & $12.1 \pm 3.6$ & ns \\
\hline \multicolumn{4}{|l|}{ Fat mass } \\
\hline Arms (kg) & $0.4 \pm 0.1$ & $0.3 \pm 0.1$ & ns \\
\hline Legs (kg) & $2.0 \pm 0.6$ & $1.6 \pm 0.6$ & ns \\
\hline Trunk (kg) & $2.5 \pm 0.8$ & $2.1 \pm 0.8$ & $\mathrm{~ns}$ \\
\hline Total body (kg) & $10.3 \pm 3.1$ & $8.7 \pm 3.0$ & ns \\
\hline \multicolumn{4}{|l|}{ Lean } \\
\hline Arms (kg) & $3.4 \pm 0.5$ & $3.4 \pm 0.6$ & ns \\
\hline Legs (kg) & $9.9 \pm 1.0$ & $9.8 \pm 1.2$ & ns \\
\hline Trunk (kg) & $13.4 \pm 1.5$ & $13.5 \pm 1.3$ & ns \\
\hline Total body (kg) & $57.2 \pm 5.5$ & $57.6 \pm 5.8$ & ns \\
\hline \multicolumn{4}{|l|}{ BMC } \\
\hline Arms $(\mathrm{g} / \mathrm{cm})$ & $0.2 \pm 0.03$ & $0.2 \pm 0.03$ & ns \\
\hline Legs $(\mathrm{g} / \mathrm{cm})$ & $0.6 \pm 0.07$ & $0.6 \pm 0.06$ & ns \\
\hline Trunk (g/cm) & $0.6 \pm 0.09$ & $0.6 \pm 0.07$ & ns \\
\hline Total body $(\mathrm{g} / \mathrm{cm})$ & $3.1 \pm 0.4$ & $3.2 \pm 0.3$ & ns \\
\hline \multicolumn{4}{|l|}{ BMD } \\
\hline Total body $\left(\mathrm{g} / \mathrm{cm}^{2}\right)$ & $1.227 \pm 0.082$ & $1.278 \pm 0.067$ & ns \\
\hline
\end{tabular}

Notes: Mean \pm SD. ${ }^{a}$ The upper limb is the sum of the upper arm and the forearm and hand; b the lower limb is the sum of the thigh and the lower thigh and foot. Abbreviations: ns, not significant; BMC, bone mineral content; BMD, bone mineral density; BMI, body mass index; SD, standard deviation.

$P<0.001)$, but significantly shorter stroke distance $(\mathrm{C}$ : $3.2 \pm 0.2 \mathrm{~m} /$ times; K: $2.1 \pm 0.1 \mathrm{~m} /$ times; $P<0.001)$. Moreover, no significant difference was seen in blood lactate immediately after the completion of exercise (C: $11.1 \pm 3.3 \mathrm{mmol} / \mathrm{L}$; $\mathrm{K}: 13.2 \pm 2.0 \mathrm{mmol} / \mathrm{L} ; P<0.001)$. 
Table 2 Comparisons of physical characteristics in canoe and kayak paddlers

\begin{tabular}{llll}
\hline & Canoe & Kayak & $P$ \\
\hline Fitness test & & & \\
Grip strength $(\mathrm{kg})$ & $50.0 \pm 11.5$ & $50.6 \pm 7.9$ & $\mathrm{~ns}$ \\
Back strength $(\mathrm{kg})$ & $146.9 \pm 29.4$ & $151.5 \pm 23.4$ & $\mathrm{~ns}$ \\
Sit-up (times) & $34.8 \pm 6.2$ & $33.8 \pm 8.0$ & $\mathrm{~ns}$ \\
Sit and reach $(\mathrm{cm})$ & $49.2 \pm 6.9$ & $51.6 \pm 7.9$ & $\mathrm{~ns}$ \\
Abalakov test $(\mathrm{cm})$ & $55.5 \pm 5.0$ & $56.0 \pm 7.3$ & $\mathrm{~ns}$ \\
Squat jump $(\mathrm{cm})$ & $42.3 \pm 4.2$ & $44.2 \pm 5.1$ & $\mathrm{~ns}$
\end{tabular}

Maximum oxygen uptake

$\dot{\mathrm{V}}{ }_{2 \text { max }}$
$\mathrm{L} / \mathrm{min}$
$\mathrm{mL} / \mathrm{kg} / \mathrm{min}$
Blood lactate
$\mathrm{HR}_{\text {max }}(\mathrm{bpm})$
Wingate t
$P_{\text {ave }}(\mathrm{W})$
$P_{\text {peak }}(\mathrm{W})$
$P_{\text {ave }}(\mathrm{W} / \mathrm{kg})$
$P_{\text {peak }}(\mathrm{W} / \mathrm{kg})$
IRM

Back squat $(\mathrm{kg})$

Bench press $(\mathrm{kg})$

Isokinetic of knee strength

$60 \% \mathrm{~s}$

Extension $(\mathrm{N} \cdot \mathrm{m})$

Flexion $(\mathrm{N} \cdot \mathrm{m})$

Extension $(\mathrm{N} \cdot \mathrm{m} / \mathrm{kg})$

Flexion $(\mathrm{N} \cdot \mathrm{m} / \mathrm{kg})$

$180 \%$ s

\begin{tabular}{llll} 
Extension $(\mathrm{N} \cdot \mathrm{m})$ & $125.4 \pm 26.0$ & $128.3 \pm 17.3$ & $\mathrm{~ns}$ \\
Flexion $(\mathrm{N} \cdot \mathrm{m})$ & $87.2 \pm 22.5$ & $85.7 \pm 13.4$ & $\mathrm{~ns}$ \\
Extension $(\mathrm{N} \cdot \mathrm{m} / \mathrm{kg})$ & $1.8 \pm 0.2$ & $1.9 \pm 0.3$ & $\mathrm{~ns}$ \\
Flexion $(\mathrm{N} \cdot \mathrm{m} / \mathrm{kg})$ & $1.2 \pm 0.2$ & $1.2 \pm 0.2$ & $\mathrm{~ns}$ \\
$300 \%$ & & & \\
Extension $(\mathrm{N} \cdot \mathrm{m})$ & $98.0 \pm 19.9$ & $100.3 \pm 14.6$ & $\mathrm{~ns}$ \\
Flexion $(\mathrm{N} \cdot \mathrm{m})$ & $75.4 \pm 20.1$ & $72.0 \pm 11.3$ & $\mathrm{~ns}$ \\
Extension $(\mathrm{N} \cdot \mathrm{m} / \mathrm{kg})$ & $1.4 \pm 0.2$ & $1.5 \pm 0.2$ & $\mathrm{~ns}$ \\
Flexion $(\mathrm{N} \cdot \mathrm{m} / \mathrm{kg})$ & $1.1 \pm 0.2$ & $1.0 \pm 0.1$ & $\mathrm{~ns}$ \\
\hline
\end{tabular}

Abbreviations: ns, not significant; $\mathrm{VO}_{2 \text { max }}$ maximum oxygen uptake; $\mathrm{HR}_{\max }$ maximum heart rate; $P_{\text {avg' }}$, Wingate test average power; $P_{\text {peak }}$, Wingate test peak power; IRM, one-repetition maximum.

Table 3 Comparisons of performance test in canoe and kayak paddlers

\begin{tabular}{llll}
\hline & Canoe & Kayak & $\mathbf{P}$ \\
\hline Stroke distance $(\mathrm{m} /$ times $)$ & $3.2 \pm 0.2$ & $2.1 \pm 0.1$ & $* * *$ \\
Stroke rate (times $/ \mathrm{min})$ & $62.0 \pm 3.9$ & $113.7 \pm 9.1$ & $* * *$ \\
$P_{\text {ave }}(\mathrm{W})$ & $183.1 \pm 47.6$ & $346.7 \pm 54.9$ & $* * *$ \\
$P_{\text {peak }}(\mathrm{W})$ & $120.5 \pm 27.0$ & $201.8 \pm 26.4$ & $* * *$ \\
Blood lactate $(\mathrm{mmol} / \mathrm{L})$ & $11.1 \pm 3.3$ & $13.2 \pm 2.0$ & $\mathrm{~ns}$ \\
\hline
\end{tabular}

Notes: Mean \pm SD; $* * * P<0.001$.

Abbreviations: ns, not significant; $P_{\text {avg }}$, Wingate test average power; $P_{\text {peak }}$, Wingate test peak power; SD, standard deviation.

$109.1 \pm 20.2 \quad 103.8 \pm 17.8 \quad$ ns

$2.8 \pm 0.3 \quad 2.8 \pm 0.4 \quad$ ns

Relationship between physical characteristics and performance test

Table 4 shows the correlation coefficients between performance test and absolute size characteristics of canoe and kayak paddlers. In canoe paddlers, performance test was

Table 4 Correlation coefficients between performance test and absolute size characteristics of canoe and kayak paddlers

\begin{tabular}{lll}
\hline & Canoe & Kayak \\
\hline Age $(\mathrm{yr})$ & -0.313 & -0.266 \\
Career $(\mathrm{yr})$ & -0.015 & 0.036 \\
Height $(\mathrm{cm})$ & 0.549 & $0.639^{*}$ \\
Body mass $(\mathrm{kg})$ & $0.878^{* *}$ & $0.825^{* *}$ \\
BMI & $0.803^{* *}$ & $0.625^{*}$
\end{tabular}

Anthropometric characteristics

Segment length $(\mathrm{cm})$

Arm span

0.533

$0.705^{*}$

Sitting height

0.545

0.540

Upper limb

$0.778 * *$

$0.726 * *$

Lower limb

0.395

$0.621^{* *}$

Girth $(\mathrm{cm})$

Neck

$0.649 *$

0.567

Chest

Waist

$0.928 * *$

$0.826 * *$

Hip

$0.80 I^{* *}$

$0.743 * *$

Arm

Forearm

$0.768 * *$

$0.752 * *$

Thigh

Calf

0.820 **

0.714

0.452

$0.78 I^{* *} \quad 0.569$

$0.753^{* *} \quad 0.905 * *$

\section{Body composition}

Body fat (\%)

Arms

0.121

0.397

Legs

0.233

0.253

Trunk

0.333

0.288

Total body

0.269

0.280

Fat mass (kg)

Arms

0.445

$0.594 *$

Legs

0.395

0.518

Trunk

Total body

0.598

0.429

Lean $(\mathrm{kg})$

Arms

0.500

0.515

Legs

$0.900 * *$

$0.895^{* *}$

$0.767 * * \quad 0.845 * *$

Trunk

Total body

$0.869 * *$

$0.640 *$

BMC $(\mathrm{kg})$

Arms

$0.913 * *$

$0.824 * *$

Legs

Trunk

$0.854 * *$

$0.798 * *$

$0.819 * * \quad 0.540$

$0.772 * * \quad 0.397$

Total body

$0.783^{* *}$

0.520

BMD $\left(\mathrm{g} / \mathrm{cm}^{2}\right)$

Total body

0.368

$-0.232$

Notes: $* * P<0.01$; $* P<0.05$.

Abbreviations: BMI, body mass index; BMC, bone mineral content; BMD, bone mineral density. 
positively correlated with body mass $(70.8 \pm 7.8 \mathrm{~kg}, r=0.878$, $P<0.01)$, BMI $(23.7 \pm 1.9, r=0.803, P<0.01)$, upper limb length $(78.3 \pm 2.8 \mathrm{~cm}, r=0.778, P<0.01)$, neck girth $(37.3 \pm 1.8$ $\mathrm{cm}, r=0.649, P<0.05)$, chest girth $(94.6 \pm 6.3 \mathrm{~cm}, r=0.928$, $P<0.01)$, waist girth $(78.9 \pm 4.4 \mathrm{~cm}, r=0.801, P<0.01)$, hip girth $(92.3 \pm 4.0 \mathrm{~cm}, r=0.768, P<0.01)$, arm girth (31.5 $\pm 2.5 \mathrm{~cm}, r=0.876, P<0.01)$, forearm girth $(26.7 \pm 2.0$ $\mathrm{cm}, r=0.820, P<0.01)$, thigh girth $(54.7 \pm 2.8 \mathrm{~cm}, r=0.781$, $P<0.01)$, calf girth $(36.4 \pm 1.9 \mathrm{~cm}, r=0.753, P<0.01)$, arm lean body mass $(3.4 \pm 0.5 \mathrm{~kg}, r=0.900, P<0.01)$, leg lean body mass $(9.9 \pm 1.0 \mathrm{~kg}, r=0.767, P<0.01)$, trunk lean body mass $(13.4 \pm 1.5 \mathrm{~kg}, r=0.869, P<0.01)$, total lean body mass $(57.2 \pm 5.5 \mathrm{~kg}, r=0.913, P<0.01)$, arm BMC $(0.2 \pm 0.03$ $\mathrm{kg}, r=0.854, P<0.01)$, leg BMC $(0.6 \pm 0.07 \mathrm{~kg}, r=0.819$, $P<0.01)$, trunk BMC $(0.6 \pm 0.09 \mathrm{~kg}, r=0.772, P<0.01)$, and total body BMC $(3.1 \pm 0.4 \mathrm{~kg}, r=0.783, P<0.01)$. Especially, there were "nearly perfect" positive correlations with chest circumference and lean mass of arm and total body $(r>0.9)$.

In kayak paddlers, performance test was positively correlated with height $(172.8 \pm 5.3 \mathrm{~cm}, r=0.639, P<0.05)$, body mass $(69.5 \pm 7.8 \mathrm{~kg}, r=0.825, P<0.01)$, BMI $(23.2 \pm 2.1$, $r=0.625, P<0.05)$, arm span $(177.4 \pm 8.0 \mathrm{~cm}, r=0.705$, $P<0.05)$, upper limb length $(78.0 \pm 3.2 \mathrm{~cm}, r=0.726, P<0.01)$, leg length $(89.2 \pm 3.3 \mathrm{~cm}, r=0.621, P<0.05)$, chest girth (93.9 $\pm 5.7 \mathrm{~cm}, r=0.826, P<0.01)$, waist girth $(78.6 \pm 5.2$ $\mathrm{cm}, r=0.743, P<0.01)$, hip girth $(91.9 \pm 3.9 \mathrm{~cm}, r=0.752$, $P<0.01)$, calf girth $(36.6 \pm 1.7 \mathrm{~cm}, r=0.905, P<0.01)$, arm fat mass $(0.3 \pm 0.1 \mathrm{~kg}, r=0.594, P<0.05)$, arm lean body mass $(3.4 \pm 0.6 \mathrm{~kg}, r=0.895, P<0.01)$, leg lean body mass $(9.8 \pm 1.2$ $\mathrm{kg}, r=0.845, P<0.01)$, trunk lean body mass $(13.5 \pm 1.3$ $\mathrm{kg}, r=0.640, P<0.05)$, total lean body mass $(57.6 \pm 5.8 \mathrm{~kg}$, $r=0.824, P<0.01)$, and arm BMC $(0.2 \pm 0.03 \mathrm{~kg}, r=0.798$, $P<0.01)$. Especially, there was "nearly perfect" positive correlation with calf circumference $(r>0.9)$.

\section{Relationship between performance test and physical characteristics}

Table 5 shows the $r$-values for the relationship between performance test and physical characteristics of canoe and kayak paddlers. In canoe paddlers, performance test was positively associated with grip strength $(50.0 \pm 11.5 \mathrm{~kg}, r=0.745$, $P<0.01)$, back strength $(146.9 \pm 29.4 \mathrm{~kg}, r=0.846, P<0.01)$, $\mathrm{VO}_{2 \max }(3.83 \pm 0.3 \mathrm{~L} / \mathrm{min}, r=0.709, P<0.05)$, Wingate test average power $(649.9 \pm 86.4 \mathrm{~W}, r=0.816, P<0.01)$ and peak power (861.2 $\pm 121.7 \mathrm{~W}, r=0.719, P<0.05)$, bench press $(90.8 \pm 21.7$ $\mathrm{kg}, r=0.760, P<0.01)$, and isokinetic knee extension and
Table 5 Correlation coefficients between performance test and physical characteristics of canoe and kayak paddlers

\begin{tabular}{|c|c|c|}
\hline & Canoe & Kayak \\
\hline \multicolumn{3}{|l|}{ Fitness test } \\
\hline Grip strength (kg) & $0.745 * *$ & $0.636 *$ \\
\hline Back strength (kg) & $0.846 * *$ & 0.307 \\
\hline Sit-up (times) & 0.383 & 0.278 \\
\hline Sit and reach $(\mathrm{cm})$ & 0.487 & $0.696 *$ \\
\hline Abalakov test $(\mathrm{cm})$ & -0.070 & 0.162 \\
\hline Squat jump $(\mathrm{cm})$ & 0.159 & 0.340 \\
\hline \multicolumn{3}{|c|}{ Maximum oxygen uptake } \\
\hline$\dot{\mathrm{V}} \mathrm{2}_{\text {max }}(\mathrm{L} / \mathrm{min})$ & $0.709 *$ & $0.663^{*}$ \\
\hline$\dot{\mathrm{V}} \mathrm{O}_{2 \max }(\mathrm{mL} / \mathrm{kg} / \mathrm{min})$ & -0.576 & -0.503 \\
\hline Blood lactate (mmol) & 0.595 & -0.756 \\
\hline $\mathrm{HR}_{\max }(\mathrm{bpm})$ & 0.103 & -0.299 \\
\hline \multicolumn{3}{|l|}{ Wingate test } \\
\hline$P_{\text {ave }}(\mathrm{W})$ & $0.816 * *$ & $0.663^{*}$ \\
\hline$P_{\text {peak }}^{\text {ave }}(\mathrm{W})$ & $0.719 *$ & $0.63 I^{*}$ \\
\hline$P_{\text {ave. }}^{\text {peak }}(\mathrm{W} / \mathrm{kg})$ & 0.061 & 0.038 \\
\hline$P_{\text {peak }}(\mathrm{W} / \mathrm{kg})$ & -0.035 & 0.221 \\
\hline \multicolumn{3}{|l|}{ IRM } \\
\hline Back squat (kg) & 0.335 & -0.285 \\
\hline Bench press $(\mathrm{kg})$ & $0.760 * *$ & $0.587^{*}$ \\
\hline \multicolumn{3}{|c|}{ Isokinetic of knee strength } \\
\hline \multicolumn{3}{|c|}{$60 \%$} \\
\hline Extension $(\mathrm{N} \cdot \mathrm{m})$ & $0.76 I^{* *}$ & 0.506 \\
\hline Flexion $(\mathrm{N} \cdot \mathrm{m})$ & $0.784 * *$ & 0.519 \\
\hline Extension $(\mathrm{N} \cdot \mathrm{m} / \mathrm{kg})$ & 0.258 & -0.115 \\
\hline Flexion $(\mathrm{N} \cdot \mathrm{m} / \mathrm{kg})$ & 0.349 & 0.026 \\
\hline \multicolumn{3}{|l|}{$180 \% \mathrm{~s}$} \\
\hline Extension $(\mathrm{N} \cdot \mathrm{m})$ & $0.858 * *$ & 0.368 \\
\hline Flexion $(\mathrm{N} \cdot \mathrm{m})$ & $0.784 * *$ & $0.706 *$ \\
\hline Extension $(\mathrm{N} \cdot \mathrm{m} / \mathrm{kg})$ & 0.574 & -0.244 \\
\hline Flexion $(\mathrm{N} \cdot \mathrm{m} / \mathrm{kg})$ & 0.552 & 0.216 \\
\hline \multicolumn{3}{|l|}{$300 \% \mathrm{~s}$} \\
\hline Extension $(\mathrm{N} \cdot \mathrm{m})$ & $0.840 * *$ & 0.508 \\
\hline Flexion $(\mathrm{N} \cdot \mathrm{m})$ & $0.805^{* *}$ & $0.722^{* *}$ \\
\hline Extension $(\mathrm{N} \cdot \mathrm{m} / \mathrm{kg})$ & 0.497 & -0.092 \\
\hline Flexion $(\mathrm{N} \cdot \mathrm{m} / \mathrm{kg})$ & 0.573 & 0.251 \\
\hline
\end{tabular}

Notes: $* * P<0.01 ; * P<0.05$.

Abbreviations: $\dot{\mathrm{V}}_{2 \text { max }}$, maximum oxygen uptake; $\mathrm{HR}_{\text {max }}$ maximum heart rate; $P_{\text {avg' }}$ Wingate test average power; $P_{\text {peak }}$, Wingate test peak power; IRM, one repetition maximum.

flexion strength at $60^{\circ} / \mathrm{s}$ (ext: $195.3 \pm 30.8 \mathrm{~N} \cdot \mathrm{m}, r=0.761$, $P<0.01$; flex: $109.1 \pm 20.2 \mathrm{~N} \cdot \mathrm{m}, r=0.784, P<0.01), 180^{\circ} / \mathrm{s}$ (ext: $125.4 \pm 26.0 \mathrm{~N} \cdot \mathrm{m}, r=0.858, P<0.01$; flex: $87.2 \pm 22.5$ $\mathrm{N} \cdot \mathrm{m}, r=0.784, P<0.01)$, and $300^{\circ} / \mathrm{s}($ ext: $98.0 \pm 19.9 \mathrm{~N} \cdot \mathrm{m}$, $r=0.840, P<0.01$; flex: $75.4 \pm 20.1 \mathrm{~N} \cdot \mathrm{m}, r=0.805, P<0.01)$. Significantly "very large" positive correlations were observed with all parameters $(r>0.7)$.

In kayak paddlers, performance test was positively associated with grip strength $(50.6 \pm 7.9 \mathrm{~kg}, r=0.636, P<0.05)$, sit and reach $(51.6 \pm 7.9 \mathrm{~cm}, r=0.696, P<0.05), \mathrm{VO}_{2 \max }$ 
(3.83 $\pm 0.3 \mathrm{~L} / \mathrm{min}, r=0.663, P<0.05)$, Wingate test average power $(640.3 \pm 82.9 \mathrm{~W}, r=0.663, P<0.05)$ and peak power $(841.1 \pm 134.5 \mathrm{~W}, r=0.631, P<0.05)$, bench press $(83.8 \pm 18.6$ $\mathrm{kg}, r=0.587, P<0.05)$, and isokinetic knee flexion strength at $180 \% \mathrm{~s}(85.7 \pm 13.4 \mathrm{~N} \cdot \mathrm{m}, r=0.706, P<0.05)$ and $300 \%$ $(72.0 \pm 11.3 \mathrm{~N} \cdot \mathrm{m}, r=0.722, P<0.01)$. Furthermore, correlations with absolute values alone were seen for $\mathrm{VO}_{2 \max }$, Wingate test average and peak power, and isokinetic knee extension and flexion strength in both canoe and kayak paddlers. Kayak paddlers showed a "very large" positive correlation with isokinetic knee flexion strength at $180 \%$ s and $300^{\circ} / \mathrm{s}(r>0.7)$.

\section{Discussion}

Since the pattern of movement in canoe sprint differs apparently between canoe and kayak, the physical characteristics and fitness may also vary between the competitions. In the present study, we investigated the association between performance test on an ergometer and physical characteristics and fitness in university canoe sprinters. Our results did not reveal significant differences in any of the measurement items for anthropometric characteristics, body composition, and fitness (Tables 1 and 2). On the other hand, the relationship between performance test and each measurement item according to the discipline showed that isokinetic knee extension and flexion strength at a low speed was important in canoe paddlers. Moreover, arm and calf girth were found to be important in canoe paddlers, while height, arm span, and leg length were important in kayak paddlers.

\section{Comparisons of physical characteristics and fitness in canoe and kayak paddlers}

According to previous studies, elite canoe sprinters in Japan tend to have a height of $171.2 \pm 5.5 \mathrm{~cm}$ and a body mass of $71.8 \pm 8.2 \mathrm{~kg}^{22}$ in the case of canoe paddlers, and a height of $172.3 \pm 4.6 \mathrm{~cm}$ and a body mass of $70.9 \pm 7.1 \mathrm{~kg}^{23}$ in the case of kayak paddlers, which are similar to the physical characteristics of the athletes in the present study. In terms of fitness, our values for grip strength, sit up, bench press, and $\mathrm{VO}_{2 \text { max }}$ were almost the same as those in previous studies..$^{5,12}$ The collegiate canoe sprinters in the present study, therefore, had same physiques and fitness. We showed no significant difference between disciplines in any of the anthropometric characteristics, body composition, or fitness parameters in the present study. This was likely due to the fact that both canoe and kayak paddlers were from the same team and shared the same training program, which made the effect of weight training greater than that of training on water.

\section{Relationship between performance test and measurement items}

A study that investigated the correlation of body composition and power output by a cycle ergometer showed that the power output in the high body fat group was lesser than that in the low body fat group. ${ }^{24}$ Regarding handball players, it reported that body fat has a negative effect on power output. ${ }^{25}$ In our study, although no significantly correlation was observed with performance test and body fat, physical performance was positively correlated with the physical characteristics of body mass, upper limb length, chest girth, waist girth, hip girth, calf girth, arm lean body mass, leg lean body mass, trunk lean body mass, total lean body mass, and arm BMC in both canoe and kayak paddlers. Moreover, in canoe paddlers, the performance test was positively correlated with the physical characteristics of neck girth, arm girth, forearm girth, thigh girth, and BMC (arms, trunk, and total body), while in kayak paddlers, positive correlations were seen with height, arm span, leg length, and arm fat mass (Table 4). Top level athletes, such as Olympic and World Championship medalists, have a mean height of $184.3 \pm 5.8 \mathrm{~cm}$ and a body mass of $85.2 \pm 6.2 \mathrm{~kg},{ }^{4}$ which are clearly greater than those of Japanese athletes, including those in our study. Moreover, top-level athletes throughout the world are reported to have less body fat and more lean body mass. ${ }^{26}$ We also saw a relationship between performance test and body and muscle mass in the present study, which is considered important to increasing the lean body mass in order to improve the performance in canoe sprint.

In addition, we found that performance test was positively correlated with grip strength, $\mathrm{VO}_{2 \text { max }}$, the Wingate test (average and peak power), bench press, and isokinetic knee flexion strength $\left(180^{\circ} / \mathrm{s}, 300^{\circ} \mathrm{s}\right)$ in both canoe and kayak paddlers (Table 5). The paddling motion in kayak mainly involves arm and trunk muscles, and it is necessary to activate the bilateral extensors and flexors of the hips and knees to simultaneously twist the body. Moreover, because the stroke rate is higher with kayak than it is with canoe, force needs to be exerted at a high speed. On the other hand, the upper body is greatly anteverted when the paddle enters the water during canoe paddling. At this time, the legs also work to extend and flex the knee joint. Furthermore, after the paddle enters the water, paddling is achieved by lifting the upper body while twisting the back, trunk muscles, and hip joints. Compared 
with kayak, the stroke rate of canoe is slower, although each stroke distance is greater. Therefore, a greater amount of force needs to be exerted per stroke. The performance test was positively correlated with back strength, isokinetic knee extension $(60 \%$ s, $180 \%$ s, 300\% $)$ and flexion strength $(60 \%)$ in canoe paddlers, and with sit and reach in kayak paddlers (Table 5). The results of the present study likely reflect the characteristics of the paddling motion of both competitions. Our findings suggested that back strength and force exerted by the legs at a slow speed are particularly important in canoe paddlers as compared with kayak paddlers.

The present study had the following three limitations. First, the canoe and kayak ergometer used in the present study was useful in evaluating performance. ${ }^{20}$ However, it does not reflect balance and technical factors on the water. It will therefore be necessary to investigate the association between actual race time and physical and fitness characteristics. In particular, it has been reported that gaining speed in the early stage of the race and preventing a reduction in speed in the final stage is important in order to improve performance on the water. ${ }^{27}$ It is therefore necessary to investigate the speed at the start, middle, and end of the race in detail. It has also been reported that anaerobic power in the upper limbs is important in kayak. ${ }^{13}$ To further elucidate the characteristics of each discipline, anaerobic capacity of isokinetic muscle strength of the upper limbs (elbow, shoulder, and wrist joints) and of arm cranking using the upper limbs and so forth may need to be measured. Second, the sample size was small. Further study with a bigger sample size is needed to investigate how the factors affect the performance in canoe and kayak paddlers, using multiple regression analyses. The final limitation is the repeatability of measurements. The performance tests and anthropometric tests were performed by well-trained investigators in this study. Although we believe that measurement bias could be suppressed, we could not exclude the possibility of it. Further study may be required for repeated measurements and evaluations using precision mechanical equipment such as ultrasound or magnetic resonance imaging.

\section{Conclusion}

The present study compared the relationship between performance test and physical and fitness characteristics in canoe and kayak, which are both disciplines in canoe sprint. We observed no differences in physical and fitness characteristics between the two disciplines. However, our findings suggested that factors associated with performance differ according to the competition. Therefore, we conclude that it is necessary to implement a different training program depending on the type of canoe sprint. The findings of this study will be useful data to consider while planning the training programs and discovering talented athletes.

\section{Disclosure}

The authors report no conflicts of interest in this work.

\section{References}

1. Shephard RJ. Science and medicine of canoeing and kayaking. Sports Med. 1987;4(1):19-33.

2. Naka T, Han I, Ohno M. Right and left segmental body composition in female basketball players and swimmers. Bull Nippon Sport Sci Univ. 2008;38(1):1-8. Japanese.

3. Robinson MG, Holt LE, Pelham TW. The technology of sprint racing canoe and kayak hull and paddle designs. Int Sports J. 2002;6:68-85.

4. Ackland TR, Ong KB, Kerr DA, Ridge B. Morphological characteristics of Olympic sprint canoe and kayak paddlers. J Sci Med Sport. 2003;6(3):285-294.

5. Nakagaki K, Yoshihisa T, Umemura Y, Nabekura Y. Characteristics of physical ability in Japanese flat-water kayak paddlers. J Train Sci Exerc Sport. 2006;18(3):229-239. Japanese.

6. Misigoj-Duraković M, Heimer S. Characteristics of the morphological and functional status of kayakers and canoeists. J Sports Med Phys Fitness. 1992;32(1):45-50.

7. Tanaka N, Tsujita J, Hori S, Senga Y, Otsuki T, Yamazaki T. Studies on physique and body shape of athletes with special reference to differences in physique among athletes of various kinds of sports. Jpn Soc Phys Fitness Sport Med. 1997;26:114-123. Japanese.

8. Enoki T, Nakagawa M, Imai Y. Relationship between body composition and physical strength characteristics in collegiate American football players. Bull Osaka Kyoiku Univ. 2013;61(2):47-53. Japanese.

9. Tsuchiya Y, Ochi E, Sakuraba K, Kikuchi N, Hwang I. Isokinetic strength and anaerobic/intermittent capacity of Japanese lacrosse players. Isokinetic Exerc Sci. 2013;21(1):77-82.

10. Watanabe N, Enomoto Y, Ohyama BK, Miyashita K, Ogata M, Katsuta S. Relationships between movement as well as joint torque during sprint running and isokinetic maximal strength. Jpn J Phys Educ Health Sport Sci. 2003;48:405-419. Japanese.

11. Miyamori T, Yoshimura M, Ayabe M, Miyahara Y, Aoba Y, Suzuki S. Characteristics of physical abilities of college soccer players according to their usual playing position - relationships of the distance and speed of movements during a game with physiologic characteristics. Rigakuryoho Kagaku. 2008;23(2):189-195.

12. Hashimoto A, Nakamura N, TakaiY, Masayoshi Y. Relationship between morphological characteristic/power output and performance of time in university sprint kayak paddlers. J Sport Train Sci. 2011;12:1-8. Japanese.

13. Isaka T, Takahashi K. Aerobic and anaerobic power and muscle thickness of varsity kayak paddlers. Jpn Soc Phys Fitness Sport Med. 1998; 47:295-304. Japanese.

14. Scott LM, Larry EH. The flatwater kayak stroke. NSCA J. 1985;7(5): 4-11.

15. van Someren KA, Palmer GS. Prediction of 200-m sprint kayaking performance. Can J Appl Physiol. 2003;28(4):505-517.

16. Marfell-Jones M. Kinanthropometric Assessment. Guidelines for Athlete Assessment in New Zealand Sport. Wellington, New Zealand: Sport Science New Zealand; 1991.

17. Muramatsu E, Otoki K, Igawa S. Assessment of body composition by segmental bioelectrical impedance method in Japanese college athletes - focus on the different characteristic of sports. NSSU J Sport Sci. 2012;1:28-25. Japanese.

18. Yamaji K. Athlete's $V_{2 \text { max }}$ Science of the Maximal Oxygen Intake. 2nd ed. Yasubayashi Study; 2001. Japanese. 
19. Thomas RB, Roger WE. Essentials of Strength Training and Conditioning. 3rd ed. Champaign, IL: Human Kinetics; 2008.

20. Nakagaki K, Yoshioka T, Nabekura Y. Development of a simplified method for assessment of metabolic capacity and characteristics of sprint kayak paddlers using the critical power model. J Train Sci Exerc Sport. 2010;22(2):111-123.

21. Cohen J. Statistical Power Analysis for the Behavioral Sciences. 2nd ed. Hillsdale, NJ: Lawrence Erlbaum Associates; 1988.

22. Fujinaka T, Yamamoto M. Investigation of the measurement and evaluation of aerobic and anaerobic capacity for canoe paddlers - using the canoe ergometer developed newly. J Sports Train Sci. 2005;6:14-23. Japanese.

23. Nakagaki K, Yoshioka T, Nabekura Y, Relationship between flat-water kayak performance and energy supply capacity. Jpn J Phys Fitness Sports Med. 2007;56:115-124. Japanese.
24. Nikolaidis PT. Body mass index and body fat per cent are associated with decreased power output in soccer players. Cent Eur J Med. 2014; 7(6):783-789.

25. Nikolaidis PT, Ingebrigtsen J. The effect of excess body mass on physical fitness in adolescent and adult male handball players. Indian J Physiol Pharmacol. 2013;57(4):369-379.

26. Sitkowski D. Some indices distinguishing Olympic or world championship medallists in sprint kayaking. Biol Sport. 2002;19(2):133-147.

27. Ikeda T, Shibuya K, Ohiwa N, Matsuo A. The reality of the race performance for Japanese top kayakers, and the aims of the race strategy for the 2008 Beijing Olympic. Jpn J Elite Sports Support. 2009;2. Japanese.

\section{Publish your work in this journal}

Open Access Journal of Sports Medicine is an international, peer-reviewed, open access journal publishing original research, reports, reviews and commentaries on all areas of sports medicine. The manuscript management system is completely online and includes a very quick and fair peer-review system.

\section{Dovepress}

Visit http://www.dovepress.com/testimonials.php to read real quotes from published authors. 